\title{
An imperative to monitor Earth's energy imbalance
}

\author{
K. von Schuckmann ${ }^{1,2^{*}}$, M. D. Palmer ${ }^{3}$, K. E. Trenberth ${ }^{4}$, A. Cazenave ${ }^{5,6}$, D. Chambers ${ }^{7}$, N.

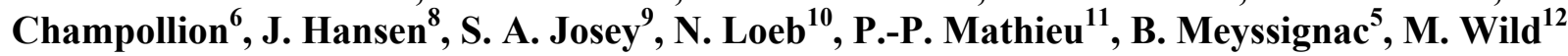 \\ 1. Mediterranean Institute of Oceanography, Université de Toulon, Aix-Marseille Université, \\ CNRS, IRD, MIO UM 110, 83041 TOULON, France \\ 2. Mercator Océan, Ramonville St Agne,France, karina.von.schuckmann@mercator-ocean.fr \\ 3. Met Office Hadley Centre, Exeter, U.K. \\ 4. National Center for Atmospheric Research, Boulder, CO, 80307, USA \\ 5. Laboratoire d'Etudes en Géophysique et Océanographie Spatiales / Centre national d'études \\ spatiales, Toulouse, France \\ 6. International Space Science Institute, Bern, Switzerland \\ 7. University of South Florida, College of Marine Science, St.Petersburg, FL, USA \\ 8. Earth Institute, Columbia University, New York, USA \\ 9. National Oceanography Centre, Southampton, U.K. \\ 10. NASA Langley Research Center, Hampton, VA, USA \\ 11. European Space Agency, Frascati, Italy \\ 12. ETH Zurich, Zurich, Switzerland
}

The current Earth's Energy Imbalance (EEI) is mostly the result of human activities and is driving global warming. The absolute value of EEI represents the most fundamental metric defining the status of global climate change and will be more useful than using global surface temperature. EEI can best be estimated from Ocean Heat Content changes, complemented by radiation measurements from space. Sustained observations from the Argo array of autonomous profiling floats and further development of the ocean observing system to sample the deep ocean, marginal seas, and the sea ice regions are crucial to refining future estimates of EEI. Combining multiple measurements in an optimal way holds considerable promise for estimating EEI and thus assessing the status of global climate change, improving climate syntheses and models, and testing the effectiveness of mitigation actions. Progress has been and can be achieved with a concerted international effort.

\section{Earth's energy imbalance}

Weather and climate on planet Earth arise primarily from differential radiative heating and resulting movement of energy by the dynamic components of the climate system: the atmosphere and the oceans. Both of these fluids can move heat and moisture through advective processes by atmospheric winds and ocean currents, as well as through eddies, large-scale atmospheric jet streams and convection. Other major components of the climate system include sea ice, the land and its features (including albedo, vegetation, other biomass, and ecosystems), snow cover, land ice (including the ice sheets of Antarctica and Greenland, and mountain glaciers), rivers, lakes, and surface and ground water. About $30 \%$ of the incoming solar radiation is reflected and scattered from clouds and the Earth's surface back to space. The remaining absorbed solar radiation (ASR) in the climate system is transformed into various forms (internal heat, potential energy, latent energy, kinetic energy, and chemical forms), moved, stored and sequestered primarily in the ocean, but also in the atmosphere, land and ice components of the climate system. Ultimately it is radiated back to space as outgoing longwave radiation $(\mathrm{OLR})^{1-3}$. In an equilibrium climate there is a global balance 
between the ASR and OLR, which determines the Earth's radiation budget ${ }^{1-2}$. Perturbations of this budget from internal or external climate variations create $\mathrm{EEI}^{4}$, manifested as a radiative flux imbalance at the top of the atmosphere (TOA).

The EEI is shaped by a number of climate forcings, some of which occur naturally and others that are anthropogenic in origin. A sense of the relative importance of these factors for a given timescale is obtained through estimates of their "Effective Radiative Forcing" (ERF, Fig. 1). The phenomena giving rise to changes in ERF vary regionally and over time. Internal climate variability occurs from day-to-day and month-to-month associated with weather systems and phenomena like the MaddenJulian Oscillation (MJO) that cause short-term changes in cloudiness ${ }^{5}$. On interannual time scales, El Niño-Southern Oscillation (ENSO) plays a substantial role as energy is taken up and stored in the ocean and then moved around and eventually discharged back into the atmosphere ${ }^{6-7}$, leading to substantial variations of EEI. Longer-term variability induced through the internal climate modes such as Pacific Decadal Oscillation (PDO) can temporarily alter the EEI for several decades as heat is sequestered by the ocean at different depths and released at a later date to the atmosphere ${ }^{8}$. All of these internal natural variations can mask any climate change signal.

Changes in the solar output with a timescale of several years (e.g., 11-year sunspot cycle), large volcanic eruptions that result in clouds of debris high in the atmosphere for a year or more, and human activities are the main external influences on EEI at decadal and longer timescales ${ }^{6,9}$ (Fig. 1). In particular, anthropogenic influences are now large enough to perturb EEI in ways that are discernible within the climate system. The latter half of the $20^{\text {th }}$ Century has seen negative contributions to EEI from anthropogenic aerosols and land use changes (Fig. 1). On decadal timescales, EEI has become increasingly dominated by the influence of carbon dioxide and other greenhouse gases, promoting the accumulation of excess heat, which is driving global warming 4,6,10-12 (Fig. 1). Over 90\% of this positive EEI is manifested in increased Ocean Heat Content (OHC) (Fig. 2a). Small amounts (a few \%) of EEI go into melting Arctic sea ice and land ice (glaciers, Greenland, Antarctica). The rest goes into warming the land and atmosphere (Fig. 2a), with changes in kinetic and chemical forms of energy several orders of magnitude smaller again. 1,13

\section{Symptoms of the EEI}

Climate change occurs as a result of adjustments to the imposed EEI as the Earth's system tries to restore radiative equilibrium. For instance, with increased heat-trapping greenhouse gases, OLR may initially decrease, resulting in a positive EEI. Then as tropospheric temperatures rise, OLR increases again according to the Stefan-Boltzmann Law, and the positive EEI is reduced until a new equilibrium takes place. However, many additional complexities occur in reality.

In the near-term, however, EEI will be positive, resulting in global temperature rise, increased $\mathrm{OHC}$, sea level rise, and the acceleration of the hydrological cycle (Fig. 2b). These are all symptoms of EEI. Accordingly EEI represents a fundamental quantity defining the rate of anthropogenic global warming. Tracking and understanding the EEI and where the energy is sequestered, and where and when it may re-emerge, is essential to improve seasonal-to-decadal climate predictions and projections on century timescales to enable improved planning for and adaptation to climate change.

Many aspects of the climate are determined by the heat capacity of the different components of the climate system ${ }^{3}$. The atmosphere does not have much capability to store heat and its heat capacity corresponds to that of the ocean to a depth of $2.5 \mathrm{~m}(<1 \%$ of the open ocean depth). Land plays a much smaller role in the storage of heat and as a result the variability of surface air temperatures over land is a factor of two to six times greater than that over the oceans. Major ice sheets, like 
those over Antarctica and Greenland respond slowly because the penetration of heat occurs primarily through conduction and thus the effective heat capacity change from year to year is small. Although sea ice is important to the radiation budget and air-sea heat exchanges locally, the global impact is small ${ }^{3}$.

The vast majority of the accumulation of excess energy with EEI is manifested in increased $\mathrm{OHC}^{11,14}$. The largest fraction of multidecadal warming has occurred in the upper $700 \mathrm{~m}$ depth of the global ocean, but as much as $25 \%$ of OHC increase since 1971 is attributable to depths below $700 \mathrm{~m}^{14-16}$, as supported by ocean reanalysis ${ }^{17}$. Although the warming below $700 \mathrm{~m}$ is still more uncertain than the warming above $700 \mathrm{~m}$, the value is positive and significant at the $10 \%$ level $^{14}$. Moreover, present-day global mean sea level (GMSL) rise is caused by a combination of ocean warming-related thermal expansion and ocean mass addition from land ice melt and ground water depletion (Fig. 2b). Thermal expansion and changes in ocean mass contribute about $30-50 \%$ and 50 $70 \%$ of observed GMSL rise over the last century, respectively ${ }^{18}$.

There is a clear relationship between EEI and global mean surface temperature (GMST) on multidecadal timescales and this is a cornerstone of the attribution of observed climate change to anthropogenic origins ${ }^{19}$. However, the uptake of heat by the ocean acts as a buffer to climate change ${ }^{20}$, slowing the rate of surface warming. Thus, the ocean's ability to store and vertically redistribute large quantities of heat over a decade or so means that trends in GMST are an unreliable indicator of global warming on these timescales (Fig. 3) - as witnessed by both observation- and modelbased studies $^{8,11,17,21-27}$. Conversely, analysis of climate models shows that trends in global OHC place a strong constraint on EEI on interannual and longer timescales (Fig. 3b), with the other components of the energy inventory playing only a minor role ${ }^{24}$.

\section{Progress in monitoring EEI}

In order to monitor climate change most effectively, we must resolve the timescales and magnitudes associated with the major external forcings presented in Fig. 1. In addition, we must increase our understanding of regional EEI natural variations, which can mask any climate change signal. The standard deviation in monthly EEI anomalies is $\approx 0.6 \mathrm{Wm}^{-2}$ (ref.5,28), and annual average EEI can change by $1 \mathrm{Wm}^{-2}$ or more during an ENSO cycle $\mathrm{e}^{6,28,29}$. EEI variability associated with solar forcing over the 11-year solar cycle is about $0.1 \mathrm{Wm}^{-2}$ (ref.6) and the range in annual mean EEI during recent volcanic events is also about $0.1 \mathrm{Wm}^{-2}$ (ref.30), but can be 20-30 times greater immediately following strong episodic volcanic eruptions (Fig. 1), such as the Mount Pinatubo and El Chichón eruptions ${ }^{31}$. Underlying this variability is a mean 0.5 to $1 \mathrm{Wm}^{-2}$ imbalance associated with climate change $e^{4,6,12,29}$, which likely only changes a few tenths of a $\mathrm{Wm}^{-2}$ per decade. Hence, monitoring EEI requires observing systems that can reliably detect changes in EEI with an accuracy of $<0.1 \mathrm{Wm}^{-2}$ on multiannual-to-decadal timescales and $<0.5 \mathrm{Wm}^{-2}$ on subannual-to-interannual timescales. Advances in both space-borne, in situ observations and climate modeling over the past two decades means that monitoring and simulating of this most vital metric of climate change is within our grasp for the first time.

There are four approaches that can potentially be used to estimate the absolute value of EEI and its time-evolution: (i) magnitude and variations in the radiative components at TOA; (ii) estimates of energy exchanges at the Earth's surface; (iii) temporal rates of change of $\mathrm{OHC}$ and other climate system components; and (iv) simulations of EEI from state-of-the-art climate modeling. Each method has its own strengths and weaknesses, but in many ways, the various methods are complementary.

The first, and perhaps most direct, approach in monitoring variations in EEI is through satellite 
instruments orbiting Earth that observe the incoming and reflected solar and emitted thermal radiation in broad spectral regions spanning the ultraviolet to the far-infrared portions of the electromagnetic spectrum ${ }^{28,32}$. The EEI is a small residual of the TOA radiative flux components that are two orders-of-magnitude greater. As a result, it is extremely challenging to achieve the required $0.1 \mathrm{Wm}^{-2}$ absolute accuracy in EEI from satellite observations. Absolute calibration uncertainty (given as $1 \sigma$ values) alone is $0.13 \mathrm{Wm}^{-2}$ for incident solar radiation ${ }^{33}, 1 \mathrm{Wm}^{-2}$ for reflected solar, and $1.5 \mathrm{Wm}^{-2}$ for emitted thermal radiation ${ }^{34}$. In addition, there are other sources of error associated with the conversion of measured radiances to fluxes $\left(0.2 \mathrm{Wm}^{-2}\right)^{34}$, time sampling uncertainties $\left(0.2 \mathrm{Wm}^{-2}\right)^{34,36}$, and uncertainty in assuming a $20-\mathrm{km}$ reference level $\left(0.1 \mathrm{Wm}^{-2}\right)^{36}$.

Nevertheless, the satellite observations are the most useful means to track variations in EEI over a range of space and time scales. This is because most uncertainties are systematic, so that while the absolute value is uncertain, its variations are known to better than $0.3 \mathrm{~W} \mathrm{~m}^{-2}$ per decade ${ }^{34}$. TOA radiative fluxes derived from a combination of geostationary and sun-synchronous satellite instruments ${ }^{35}$ can be tracked from hourly to decadal time scales, and from $1^{\circ}$ regional to global spatial scales. Currently, the longest running continuous global TOA record is from the Clouds and the Earth's Radiant Energy System (CERES) ${ }^{34}$, which started providing usable data in March 2000. TOA radiative fluxes exhibit large amplitude high frequency fluctuations owing mainly to clouds associated with weather at daily to monthly timescales ${ }^{5}$, and show a strong relationship to ENSO at interannual timescales ${ }^{6}$. The unparalleled spatio-temporal sampling characteristics of satellite measurements provide important information with which to dis-entangle the "fingerprints" associated with different radiative forcings (Fig. 1).

Since the atmosphere and land surface have little heat capacity and have stored less than $0.03 \mathrm{~W} \mathrm{~m}^{-2}$ of heat in the last several decades ${ }^{4,49}$, the EEI can, in principle, be constrained through estimates of air-sea heat fluxes on annual timescales. The uncertainties of the surface budget arise from many sources: inadequate sampling, changing data types, observing instrument biases, incomplete knowledge of exchange processes and poor representation of key variables, e.g. cloud amount. Sensible and latent heat flux estimates are obtained using bulk formulae that depend primarily on the product of wind speed with vertical temperature and humidity gradients in the near surface atmospheric layer ${ }^{38}$. Information on these variables has been provided historically from ship observations with highly heterogeneous sampling determined by shipping routes ${ }^{39}$. In the modern era (post-1980s), reasonably accurate and well-sampled satellite estimates are available for wind speed and sea surface temperature (SST). However, satellite retrievals of near surface air temperature and humidity still contain large uncertainties ${ }^{40}$, preventing accurate estimation of latent and sensible heat fluxes from space.

Atmospheric reanalyses provide a further source of surface heat exchange estimates using a combination of bulk formula and radiative transfer model approaches. However, reanalyses exhibit large global imbalances (order $10 \mathrm{~W} \mathrm{~m}^{-2}$ ) ${ }^{41-43}$, and often large spurious temporal trends (approaching $10 \mathrm{Wm}^{-2}$ at decadal timescales) ${ }^{41,44}$, rendering them unsuitable both for accurately characterizing the long term global mean heat exchange and its temporal variability. Ship based datasets, combinations of atmospheric reanalyses with satellite data and ocean reanalyses exhibit similar problems ${ }^{38,45}$.

Surface radiative flux datasets have been inferred from satellite TOA observations using models or empirical methods to correct for atmospheric attenuation although it has been difficult to satisfactorily achieve energy budget closure. The level of agreement between satellite surface radiative fluxes and in situ observations has improved ${ }^{46,47}$ with recent datasets (e.g. CERES Energy Balanced and Filled datase $\mathrm{t}^{28}$ ). While progress towards more reliable flux datasets is being made, the uncertainties will likely be much larger than other estimates for the foreseeable future, limiting their usefulness for estimating EEI, although useful complementary information can be gleaned 
regionally.

An alternate approach is to derive the EEI through estimating the rate of change of energy storage in the climate system ${ }^{4,6,48,49}$. Given the small contributions from changes in ice, land, and the atmosphere (Fig. 2a), this approach hinges on estimates of $\mathrm{OHC}$ change ${ }^{11}$. Estimates of $\mathrm{OHC}$ are obtained from the difference of the measured temperature and a climatology along a vertical profile in the ocean. Ideally, this is integrated over the full depth of the ocean, but because of limitations in the observing system, it is typically done to a reduced depth. Before 2000, temperature measurements were most often made in the upper $700 \mathrm{~m}$ of the water column, and had uneven spatial coverage. Changes in measurement techniques and instrumentation over time resulted in $\mathrm{OHC}_{\text {biase }}{ }^{50}$ and there were large uncertainties ${ }^{51}$. Discrepancies arise from different statistical methods for spatially mapping OHC, differences in data quality control processing and data correction methods ${ }^{11}$. An international effort is under way to address some of these challenges (www.iquod.org).

A dramatic improvement in the ocean observing system has been achieved with the implementation of the global Argo array of autonomous profiling floats with high precision and accuracy anchored by modern Conductivity-Temperature-Depth (CTD) systems (http://www.argo.ucsd.edu/). This allows, for the first time, continuous monitoring of the temperature and salinity of the upper 2000 $\mathrm{m}$, with international standards of quality control. By about 2005, the Argo array had sufficient space-time sampling to yield an improved measure of $\mathrm{OHC}$ change ${ }^{27}$ with an accuracy of less than $0.3 \mathrm{Wm}^{-2}$ at decadal time scale (Fig. $4 \mathrm{~b}$ and ref (11)), and has helped to refine the ocean's contribution to the Earth's energy budget ${ }^{4}$. However, despite the tremendous technical developments of the ocean in situ observing system, coverage is not yet truly global. The deep ocean below $2000 \mathrm{~m}$ (nearly half the volume) has very few measurements. The few that are available are from sparse, but very precise, hydrographic sections from research vessels ${ }^{15,52}$. There are also gaps in the geographic coverage, with almost no floats in marginal seas (like the Indonesian $\mathrm{Sea}^{53}$ ), under ice, or polewards of $60^{\circ}$ (Fig. $4 \mathrm{a}$ ).

Indirect $\mathrm{OHC}$ estimates can be computed through combining satellite observations of GMSL ${ }^{54,55}$ and global mean ocean mass (GMOM) ${ }^{56,57}$. The residual (GMSL-GMOM) is primarily the thermal expansion component of sea level and is directly related to $\mathrm{OHC}$ change ${ }^{53,58}$. For the last decade, accurate observations of GMSL from satellite altimetry and its components (e.g., steric sea level from Argo down to $2000 \mathrm{~m}$ and GMOM from GRACE space gravimetry) allows, in principle, the deep ocean contribution to sea level rise (below 2000m) to be constrained ${ }^{53,58,59}$. The most recent estimate of global, full-depth OHC change from 2005 to 2013 based on the indirect estimate is 0.64 $\pm 0.44 \mathrm{~W} \mathrm{~m}^{-2}$ (ref.58). However, up to now, errors in the data are still too large to provide robust estimates of the deep ocean contribution over a decade ${ }^{53-56,58,60,61}$.

Climate models provide another means of estimating the time evolution of EEI and can potentially provide greater insights into the underlying mechanisms than is afforded by observations alone ${ }^{6,62,63}$. However, this depends on realistic implementation of radiative forcings (Fig. 1) and confidence in the representation of aerosols, clouds, and their interaction remains a particular challenge ${ }^{64,65}$. Representation of the radiative forcing agents in climate models must be routinely updated and implemented. For example, the CMIP5 simulations do not include the small volcanic eruptions observed during the 2000s and do not fully represent our understanding of recent solar variability (including spectral variations) and their effects on radiative forcing ${ }^{6,12,30,66}$. Careful analysis of both global and local energy budgets is required to assess the fidelity of model simulations over the historical period, to promote model improvements, and to develop observational constraints on future climate change. Climate models have played an important role in our understanding of variability in EEI and the importance of ocean heat re-arrangement in shaping variations in surface temperature and upper ocean heat content $\mathrm{t}^{21,22,24,67}$. 


\section{The way forward}

The absolute measure of EEI and how it changes over time is fundamental to climate change, and represents a critical quantity defining the current status and expectations for continued global warming because it determines how much warming is in the "pipeline" order of $0.1 \mathrm{Wm}^{-2}$ for monitoring EEI at decadal time-scales, international efforts must be fostered to i) improve our capability to derive estimates of OHC changes; ii) optimize EEI quantification and its changes over time through the combined analysis of different global observing systems; iii) combine results from ocean models, atmospheric forcing fluxes, and ocean observations; and iv) develop a synergy among climate research communities concerned with the energy flows in the Earth's system.

Analyzing GMST alone is not a robust means of tracking global warming. The only practical approach to monitoring the absolute value of EEI is through the rate of change of $\mathrm{OHC}(\mathrm{dOHC} / \mathrm{dt})$ with additional small allowances for changes in sea ice, land and atmospheric energy. There are a number of elements to this argument. First, CMIP5 climate model simulations suggest that global $\mathrm{OHC}$ becomes the dominant term in Earth's energy budget on a timescale of about 1 year $^{24}$ and therefore represents the key energy storage component for EEI on annual to multi-decadal timescales ${ }^{14}$. Second, the underlying ocean temperature observations represent an absolute geophysical measurement ${ }^{11}$. Third, change in $\mathrm{OHC}$ is a useful and robust metric because it represents the time-integral of EEI.

Reducing uncertainties of $\mathrm{OHC}$ estimates is hence critical to improve the understanding of Earth's heat storage, thereby enabling better projection of climate change over the coming decades. Because of inherent natural variability, measurement uncertainty and gaps in the current global observing systems, there is a considerable spread in global $\mathrm{OHC}$ rates, ranging from 0.1 to $0.9 \mathrm{Wm}^{-}$ ${ }^{2}$ (Fig. 4b). Consequently, closure of the observed energy budget during the recent period of most complete and accurate climate observing systems (2005-present) is elusive ${ }^{6}$. Research and development is thus required by the different communities involved in satellite altimetry, GRACE and the in situ hydrographic data processing to clearly identify the causes of errors and then reduce and eliminate them.

Currently available surface flux datasets are of insufficient accuracy to be used reliably for determination of changes in EEI since they have large unphysical trends, as previously discussed. As Numerical Weather Prediction centers move towards coupled ocean-atmosphere reanalyses there is the potential such an approach will have the accuracy required for EEI studies, but this needs to be demonstrated.

OHC can be estimated through reanalysis with a physically-based model using a coupled oceanatmosphere framework. Reanalyses take advantage of the underlying physical model to bring forward all past information and provide a more physically consistent interpolation of multi-variate observations than statistical methods. Models can assimilate Argo data along with XBTs, SSTs, sea level from altimetry, satellite gravity, and so forth ${ }^{68-71}$, but currently model biases are large and need to be accounted for. International expertise exchange and discussions have been established through the ocean reanalysis inter-comparison project ORA-IP ${ }^{71}$, which is essential to understand sources of uncertainties and model biases, thereby leading to improvements. Obtaining the time-derivative of $\mathrm{OHC}$ removes some biases but emphasizes noise, and scrutiny of dOHC/dt provides a way to help evaluate products. On average it provides the basis for obtaining the absolute value of EEI. On the other hand, satellite-based TOA measurements can measure high frequency fluctuations in EEI but not their absolute value. It therefore makes sense to combine these observations in an optimal way that capitalizes on the strengths of both. Contributions from other parts of the Earth system - though small - are important for altering EEI and must be included. These include changes in the 
cryosphere, and atmospheric and continental heat storage $\mathrm{e}^{4,48}$.

Ultimately, in order to increase our capability to predict climate and develop mitigation strategies it is an imperative to track EEI. To achieve the highest possible spatio-temporal resolution we must combine satellite estimates of EEI variations from TOA radiation measurements with estimates of the absolute value of EEI derived from the time-derivative of OHC. In order to meet this goal, future priorities must include the sustained continuation of the global ocean hydrographic observing system and its extension into the deep oceans below $2000 \mathrm{~m}$ depth, polar regions and marginal seas. Supplementary data from satellite measurements are essential. Exciting developments continue to be made in observing and analysis systems. These need to continue to make the system more efficient and capable. Coordinated international efforts such as the CLIVAR research focus CONCEPT-HEAT ${ }^{72}$ need to be maintained and fostered. These new observation products will challenge climate models and lead to their improvement. The combination of these ingredients, if continued and strengthened, will provide a basis for understanding and predicting climate change that has been impossible over the past century.

\section{Acknowledgements}

Two meetings of this international working group have been supported by the International Space Science Institute (ISSI), Bern, Switzerland.

\section{Author contributions}

$\mathrm{KvS}$ led the formulation of the paper and produced figures 2 and 4. MP produced figure 3 . The main drafts of the paper were compiled by KvS, MP and KT. All authors contributed to discussions, writing and figure development.

\section{Competing Financial Interests statement}

The authors declare no competing financial interests. 


\section{References}

1. Trenberth, K. E., \& Stepaniak, D. P. Co-variability of components of poleward atmospheric energy transports on seasonal and interannual timescales. J. Clim. 16, 3691-3705 (2003).

2. Trenberth, K. E., \& Stepaniak, D. P. Seamless poleward atmospheric energy transports and implications for the Hadley circulation. J. Clim. 16, 3706-3722 (2003).

3. Trenberth, K. E., \& Stepaniak, D. P. The flow of energy through the Earth's climate system. Quart. J. Roy. Meteor. Soc., 130, 2677-2701 (2004).

4. Hansen, J., Sato, M., Kharecha P., \& von Schuckmann, K. Earth's energy imbalance and implications. Atmos. Chem. Phys., 11, 13421-13449, doi:10.5194/acp-11-13421-2011 (2011).

5. Trenberth, K. E., Zhang, Y., Fasullo, J. T., \& Taguchi, S. Climate variability and relationships between top-of-atmosphere radiation and temperatures on Earth. J. Geophys. Res., 120, 3642-3659, doi: 10.1002/2014JD022887 (2015).

6. Trenberth, K. E., Fasullo J. T., \& Balmaseda, M. A. Earth's energy imbalance. J. Clim. 27, 3129-3144, doi: 10.1175/JCLI-D-13-00294 (2014).

7. Mayer, M., \& Haimberger, L. Poleward atmospheric energy transports and their variability as evaluated from ECMWF reanalysis data. J. Clim. 25, 734-752 (2012).

8. England, M. H., et al. Recent intensification of wind-driven circulation in the Pacific and the ongoing warming hiatus. Nature Clim. Change, 4, 222-227 (2014).

9. Myhre, G., et al. Radiative forcing of the direct aerosol effect from AeroCom Phase II simulations. Atmos. Chem. Physics, 13, 1853-1877 (2013).

10. Loeb, N. G., et al. Towards optimal closure of the earth's top-of-atmosphere radiation budget. J. Clim., 22, 748-766 (2009).

11. Abraham, J. P., et al. A review of global ocean temperature observations: Implications for ocean heat content estimates and climate change. Rev. Geophysics, 51, 450-483. doi: 10.1002/rog.20022 (2013).

12. Allan, R. P., et al. Changes in global net radiative imbalance 1985-2012. Geophys. Res. Lett., 41, doi:10.1002/2014GL060962 (2014).

13. Trenberth, K. E., Stepaniak, D. P. and Caron, J. M. Accuracy of atmospheric energy budgets from analyses. J. Climate, 15, 3343-3360 (2002).

14. Rhein, M., et al. Observations: Ocean. In: Climate Change 2013: The Physical Science Basis. (eds. Stocker, T.F., et al.). Cambridge University Press, Cambridge, United Kingdom and New York, NY, USA, pp. 255-316, doi:10.1017/ CBO9781107415324.018.

15. Levitus, S., et al. World ocean heat content and thermosteric sea level change $(0-2000 \mathrm{~m})$, 1955-2010. Geophys. Res. Lett., 39, L10603, doi:10.1029/2012GL051106. (2012).

16. Purkey, S. G., \& Johnson, G. C. Warming of global abyssal and deep Southern Ocean waters between the 1990s and 2000s: contributions to global heat and sea level rise budgets. J. Clim., 23, 6336-6351 (2010).

17. Balmaseda, M. A., Trenberth K. E., \& Kallen, E. Distinctive climate signals in reanalysis of global ocean heat content. Geophys. Res. Lett., 40, 1-6, doi:10.1002/grl.50382 (2013).

18. Church, J. A., et al. Sea Level Change. In: Climate Change 2013: The Physical Science Basis. Intergovernmental Panel on Climate Change (eds Stocker, T.F., et al.) Cambridge University Press, Cambridge, United Kingdom (2013).

19. Bindoff, N. L. et al. Detection and attribution of climate change: from global to regional. Climate Change 2013 The Physical Science Basis: Intergovernmental Panel on Climate Change, (eds Stocker, T. F. et al.) Cambridge University Press, Cambridge, UK, pp. 867952 (2013).

20. Exarchou, E., Kuhlbrodt, T., Gregory, J. M. \& Smith, R. S. Ocean heat uptake processes: a model intercomparison. J. Clim., 28, 887-908, doi:10.1175/JCLI-D-14-00235.1 (2015). 
21. Meehl, G. A., Hu, A., Arblaster, J. M., Fasullo, J. T., \& Trenberth, K. E. Externally forced and internally generated decadal climate variability in the Pacific. J. Clim., 26, 7298-7310, doi:10.1175/JCLI-D-12-00548.1 (2013).

22. Palmer, M. D., McNeall, D. J., \& Dunstone, N. J. Importance of the deep ocean for estimating decadal changes in Earth's radiation balance. Geophys. Res. Lett., 38, L13707, doi:10.1029/2011GL047835 (2011).

23. Trenberth, K. E., \& Fasullo, J. T. An apparent hiatus in global warming? Earth's Future. 1, 19-32. doi: 10.002/2013EF000165 (2013).

24. Palmer M. D., \& McNeall, D. J. Internal variability of Earth's energy budget simulated by CMIP5 climate models. Environ. Res. Lett., 9 doi:10.1088/1748-9326/9/3/034016 (2014).

25. Cheng, L., \& Zhu, J. Artifacts in variations of ocean heat content induced by the observation system changes. Geophys. Res. Lett., 41, 7276-7283, doi:10.1002/2014GL061881 (2014).

26. Kosaka, Y. \& Xie, S.-P. Recent global-warming hiatus tied to equatorial Pacific surface cooling. Nature, 501, 403-408, doi:10.1038/nature12534 (2013)

27. Roemmich, D., Church, J., Gilson, J., Monselesan, D., Sutton, P., \& Wijffels, S. Unabated planetary warming and its ocean structure since 2006. Nature Clim. Change, doi: 10.1038/NCLIMATE2513 (2015).

28. Loeb, N. G., et al. Advances in understanding top-of-atmosphere radiation variability from satellite observations. Surv. Geophys., 33, 359-385. doi:10.1007/s10712-012-9175-1 (2012).

29. Loeb, N. G., et al. Observed changes in top-of-the-atmosphere radiation and upper-ocean heating consistent within uncertainty. Nat. Geosci., 5, 110-113, doi:10.1038/NGEO1375 (2012).

30. Santer, B. D., et al. Volcanic contribution to decadal changes in tropospheric temperature. Nat. Geosci., 7, 185-189, doi:10.1038/NGEO2098 (2014).

31. Minnis, P., et al. Radiative climate forcing by the Mount Pinatubo eruption. Science, 259, 1411-1415 (1993).

32. Wielicki, B. A., et al. Clouds and the Earth's Radiant Energy System (CERES): An Earth observing system experiment. Bull. Amer. Meteor. Soc. 77, 853-868 (1996).

33. Kopp, G., \& Lean, J. L. A new, lower value of total solar irradiance: Evidence and climate significance. Geophys. Res. Lett., 38, doi:10.1029/2010GL045777 (2011).

34. Loeb, N. G. et al. Toward optimal closure of the earth's top-of-atmosphere radiation budget. J. Clim., 22, 748-766 (2009).

35. Loeb, N. G., Kato, S., Loukachine, K. \& Manalo-Smith, N. Angular distribution models for top-of-atmosphere radiative flux estimation from the Clouds and the Earth's Radiant Energy System instrument on the Terra satellite. Part II: Validation. J. Atmos. Oceanic Tech., 24, 564-584 (2007).

36. Doelling, D. R., et al. Geostationary enhanced temporal interpolation for CERES flux products. J. Atmos. Ocean. Tech., 30, 1072-1090. doi:10.1175/JTECH-D-12-00136.1 (2013).

37. Loeb, N. G., Kato, S., \& Wielicki, B. A. Defining top-of-atmosphere flux reference level for earth radiation budget studies. J. Clim., 15, 3301-3309 (2002).

38. Josey, S. A., Gulev S., \& Yu, L. Exchanges through the ocean surface. Ocean Circulation and Climate 2nd Ed. A 21st century perspective, (eds Siedler, G., Griffies, S., Gould, J. \& Church, J.) Academic Press, Int. Geophys. Ser., 103, 115-140 (2013).

39. Woodruff, S. D. et al:: ICOADS Release 2.5: Extensions and enhancements to the surface marine meteorological archive. Int. J. Climatol. 31, 951-967. doi:10.1002/joc.2103 (2011).

40. Jin, X., Yu, L., Jackson, D. L. \& Wick, G. A. An Improved Near-Surface Specific Humidity and Air Temperature Climatology for the SSM/I Satellite Period. J. Atmos. Oceanic Technol., 32, 412-433. doi: 10.1175/JTECH-D-14-00080.1 (2015).

41. Bosilovich, M. G., Robertson, F. R. \& Chen, J. Global energy and water budgets in MERRA. J. Clim. 24, 5721-5739. doi:10.1175/2011JCLI4175.1 (2011). 
42. Trenberth, K. E., Fasullo, J. T., \& Mackaro, J. Atmospheric moisture transports from ocean to land and global energy flows in reanalyses. J. Clim. 24, 4907-4924, doi: 10.1175/2011JCLI4171.1 (2011).

43. Kobayashi, S., et al. The JRA-55 Reanalysis: General specifications and basic characteristics. J. Meteor. Soc. Japan, 93, doi:10.2151/jmsj.2015-001 (2015).

44. Trenberth, K. E. \& Fasullo, J. T. Regional energy and water cycles: Transports from ocean to land. J. Climate, 26, 7837-7851, doi:10.1175/JCLI-D-00008.1 (2013).

45. Valdivieso, M., et al. Surface heat fluxes from ocean and coupled reanalyses. CLIVAR Exchanges, 64 (19) (2015).

46. Kato, S., et al. Surface irradiances consistent with CERES-derived top-of-atmosphere shortwave and longwave irradiances. J. Clim., 26, 2719-2740 (2013).

47. Rutan, D. A., et al. CERES synoptic product: Methodology and validation of surface radiant flux. J. Atmos. Oceanic Technol., 32, 1121-1143. doi:10.1175/JTECH-D-14-00165.1 (2015).

48. Trenberth, K. E., Fasullo, J. T., \& Kiehl, J. Earth's global energy budget. Bull. Amer. Meteor. Soc., 90, 311-324, doi: 10.1175/2008BAMS2634.1 (2009).

49. Church, J. A., et al. Revisiting the Earth's sea-level and energy budgets from 1961 to 2008. Geophys. Res. Lett. 38, L18601, doi:10.1029/2011GL048794 (2011).

50. Gouretski, V., \& Koltermann, K. P. How much is the ocean really warming? Geophys. Res. Lett., 34, L01610, doi:10.1029/2006GL027834 (2007).

51. Lyman, J. M., et al. Robust warming of the global upper ocean. Nature, 465, 334-337, doi:10.1038/nature09043 (2010).

52. Desbruyères, D. G., et al. Full-depth temperature trends in the Northeastern Atlantic through the early 21 st century. Geophys. Res. Lett., 41, 7971-7979. 10.1002/2014GL061844 (2014).

53. von Schuckmann, K., et al. Monitoring ocean heat content from the current generation of global ocean observing systems. Ocean Science 10, 547-557, doi:10.5194/os-10-547-2012 (2014).

54. Nerem, R. S., Chambers, D. P., Choe, C., \& Mitchum, G. T. Estimating mean sea level change TOPEX and from the Jason missions. Marine Geodesy, 33, Supp. 1, 435-446, doi: 10.1080/01490419.2010.491031 (2010).

55. Ablain, M., et al. Improved sea level record over the satellite altimetry era (1993-2010) from the Climate Change Initiative project. Ocean Sci. 11, 67-82, doi:10.5194/os-11-672015 (2015).

56. Johnson, G. F., \& Chambers, D. P. Ocean bottom pressure seasonal cycles and decadal trends from GRACE release-05: Ocean circulation implications. J. Geophys. Res. Oceans 118, doi:10.1002/jgrc.20307 (2013).

57. Chen, J. L., Wilson, C. R. \& Tapley B. D. Contribution of ice sheet and mountain glacier melt to recent sea level rise. Nature Geo. 6, 549-552, doi: 10.1038/NGEO1829 (2013).

58. Llovel, W., Willis, J. K., Landerer, F. K., \& Fukumori, I. Deep-ocean contribution to sea level and energy budget not detectable over the past decade. Nature Clim. Change 4, 10311035, doi:10.1038/nclimate2387 (2014).

59. Dieng, H. B., Palanisamy, H., Cazenave, A., Meyssignac, B. \& von Schuckmann, K. The sea level budget since 2003: Inference on the deep ocean heat content Survey Geophys., 209229, doi: 10.1007/s10712-015-9314-6 (2015).

60. Dieng, H. B., Cazenave A., von Schuckmann K., Ablain M. and Meyssignac B. Sea level budget over 2005-2013: missing contributions and data errors. Ocean Science, 11, 789-802, doi:10.5194/os-11-789-2015 (2015)

61. Watson, C.S., et al. Unabated global mean sea-level rise over the satellite altimeter. Nature Clim. Change., 5, 565-568, doi:10.1038/NCLIMATE2635 (2015).

62. Smith, D.M., et al. Earth's energy imbalance since 1960 in observations and CMIP5 models. Geophys. Res. Lett. 42, 1205-1213. doi: 10.1002/2014GL062669 (2015). 
63. Wild, M., et al. The energy balance over land and oceans: An assessment based on direct observations and CMIP5 climate models. Clim. Dyn., 44, 3393-3429, doi: 10.1007/s00382014-2430-z (2015).

64. Trenberth, K. E., \& Fasullo, J. T. Tracking Earth's energy. Science, 328, 316-317 (2010).

65. Regayre, L. A., et al. Uncertainty in the magnitude of aerosol-cloud radiative forcing over recent decades. Geophys. Res. Lett., 41, 9040-9049, doi:10.1002/2014GL062029 (2014).

66. Haigh J. D., et al. An influence of solar spectral variations on radiative forcing of climate. Nature, 467, 696-699, ISSN:0028-0836 (2010).

67. Katsman, C. A., \& van Oldenborgh, G. J. Tracing the upper ocean's "missing heat". Geophys. Res. Lett., 38, L14610, doi:10.1029/2011GL048417 (2011).

68. Koehl, A., \& Stammer, D. Decadal sea level changes in the 50-year GECCO ocean synthesis, J. Clim., 21, 1876-1890, doi:10.1175/2007JCLI2081.1 (2007).

69. Carton, J. A., \& Santorelli, A. Global decadal upper-ocean heat content as viewed in nine analyses. J. Clim., 21, 6015-6035 (2008).

70. Balmaseda, M. A., Mogensen K., \& Weaver A. T. Evaluation of the ECMWF ocean reanalysis system ORAS4. Q. J. R. Meteorol. Soc. 139, 1132-1161. doi:10.1002/qj.2063 (2013).

71. Balmaseda, M. A., et al. The Ocean Reanalyses Intercomparison Project (ORA-IP). J Oper. Oceanogr., 8, doi:10.1080/1755876X.2015.1022329 (2015).

72. von Schuckmann, K., et al. : A prospectus for the CLIVAR research focus "Consistency between planetary energy balance and ocean heat storage (CONCEPT-HEAT)". Community white paper WCRP/CLIVAR, http://www.clivar.org/sites/default/files/documents/research_foci/heatbudget/prospectus_RF_OHC_FINAL.pdf(2014)

73. Myhre, G., et al. Anthropogenic and Natural Radiative Forcing. In: Climate Change 2013: The Physical Science Basis. (eds. Stocker, T.F., et al.). Cambridge University Press, Cambridge, United Kingdom and New York, NY, USA, pp. 659-740, doi:10.1017/ CBO9781107415324.018.

74. von Schuckmann, K. \& Le Traon, P.-Y. How well can we derive global ocean indicators from Argo data? Ocean Sci., 7, 783-791, doi:10.5194/os-7-783-2011 (2011).

75. Roemmich, D., \& Gilson, J. The 2004-2008 mean and annual cycle of temperature, salinity, and steric height in the global ocean from the Argo Program. Progr. Oceanogr., 82, 81-100 (2009).

76. Good, S. A., Martin M. J., \& Rayner, N. A. EN4: quality controlled ocean temperature and salinity profiles and monthly objective analyses with uncertainty estimates. J. Geophys. Res. Oceans, 118, 6704-6716, doi:10.1002/2013JC009067 (2013).

77. Hosoda, S., Ohira, T., Sato, K., \& Suga, T. Improved description of global mixed-layer depth using Argo profiling floats. J. Oceanogr. 66, 773-787 (2010). 


\section{Figure captions}

Figure 1: (adapted with permission after AR5, Fig 8.18) ${ }^{73}$ : In addition to radiative forcing from greenhouse gas concentrations, EEI is shaped by a number of additional climate forcings, some of which occur naturally (such as variations in solar output and volcanic aerosol emissions) and some of which are anthropogenic in origin (such as variations in albedo associated with land-use changes and various aerosol emissions). A sense of the relative importance of these factors for a given timescale is obtained through estimates of their Effective Radiative Forcing (ERF). ERF is defined as the change in net downward TOA radiation, once the initial adjustment of atmospheric temperatures, clouds and moisture has taken place, but before surface temperatures have responded ${ }^{9}$.

Figure 2 Schematic representations on the flow and storage of energy in the Earth's climate system and related consequences. a) EEI as resulting from human activities. The global ocean is the major heat reservoir with about $90 \%$ of EEI stored in the ocean. The rest goes into warming the land and atmosphere, as well as into melting ice. b) "Symptoms" of positive EEI, include rise in Earth's surface temperature, ocean heat content, ocean mass, global mean sea level, atmospheric temperature and moisture, drought, flooding and erosion, increased extreme events, and evaporation - precipitation (E-P), as well as a decrease in land and sea ice, snow cover, and glaciers.

Figure 3: Characterization of the relationships between changes in global surface temperature, global ocean heat content $(\mathrm{OHC})$ and Earth system energy content on decadal timescales. Discrete linear decadal trends in total energy (expressed in $\mathrm{W} \mathrm{m}^{-2}$ ) regressed against: a) contemporaneous decadal trends in globally averaged surface temperature $\left(\mathrm{K} \mathrm{dec}^{-1}\right)$; b) contemporaneous decadal trends in full-depth, global OHC $\left(\mathrm{W} \mathrm{m}^{-2}\right)$. Data are presented as 2-D histograms with higher relative frequency indicated by lighter colors. Note that the trend in total energy is equivalent to the average net top-of-atmosphere radiation over the same period. Results have been aggregated using 14,000 years of combined pre-industrial control simulation from the 24 CMIP5 models ${ }^{23}$. All energy fluxes are expressed relative to the surface area of the Earth.

Figure 4: Schematic representation of Argo observing system sampling and related ocean heat content estimates. a) Current potential of the Argo observing system with regular measurements of in situ temperature and salinity between $60^{\circ} \mathrm{S}-60^{\circ} \mathrm{N}$ in the $10-2000 \mathrm{~m}$ ocean depth layer, and remaining challenges. In particular, marginal seas and the upper $10 \mathrm{~m}$ depth are currently under-sampled, and few Argo measurements exist below $2000 \mathrm{~m}$ depth and polewards of $60^{\circ}$ latitude. b) Rates of changes for $\mathrm{OHC}$ over the upper 2000m depth layer as obtained from the Argo observing system between 2006 and 2012, and their error bars ( \pm 1 standard deviation), as processed from different working groups, i.e. after (ref 74) (magenta) and obtained from freely available gridded fields (SCRIPPS $^{75}$ (blue); IPRC (black, http://apdrc.soest.hawaii.edu/projects/argo/); $\mathrm{EN}^{76}$ (green); JAMSTEC ${ }^{77}$ (cyan). Results from the indirect method via the global sea level budget have been added as well ${ }^{58}(\mathrm{red})$. 


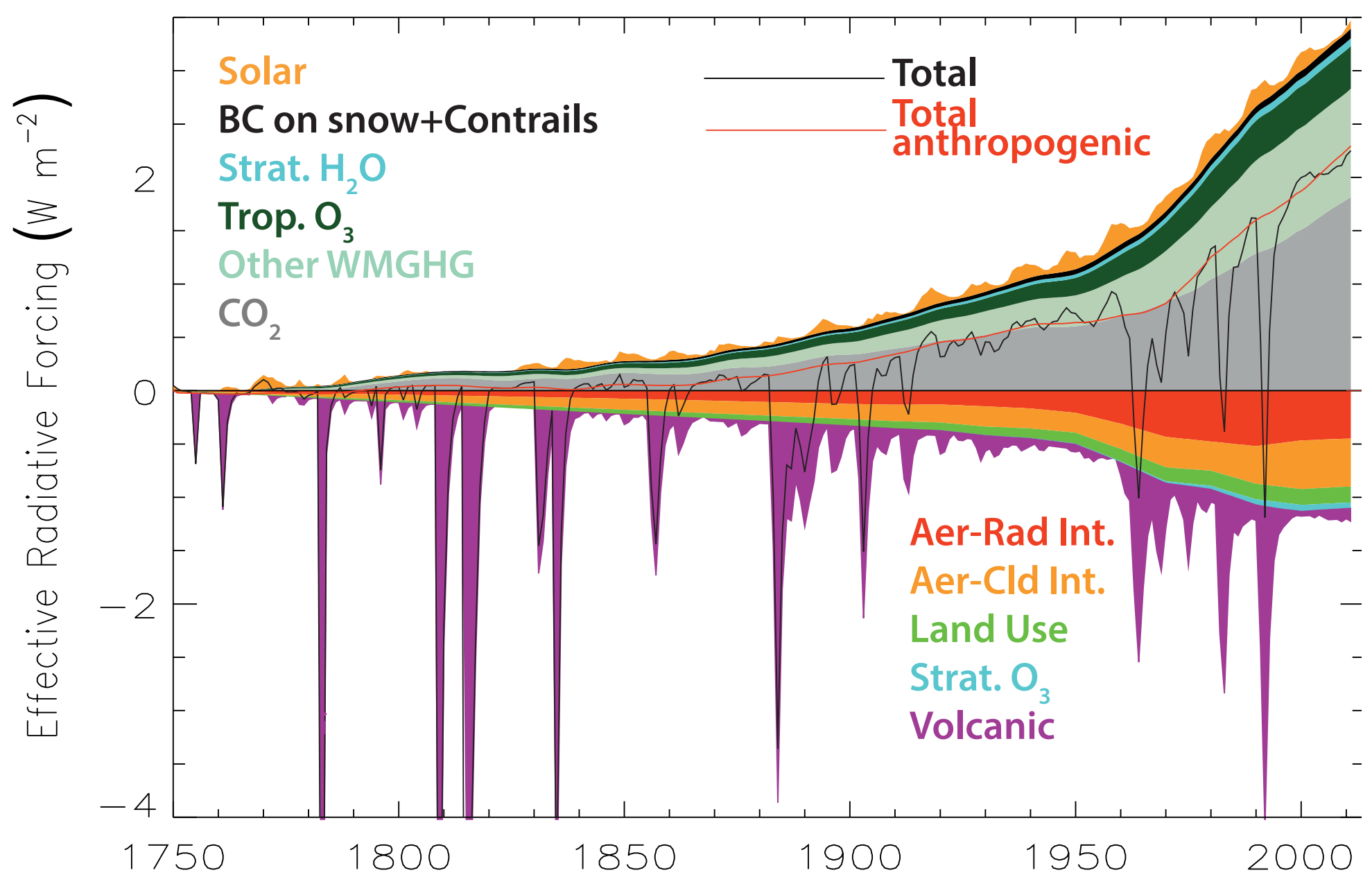




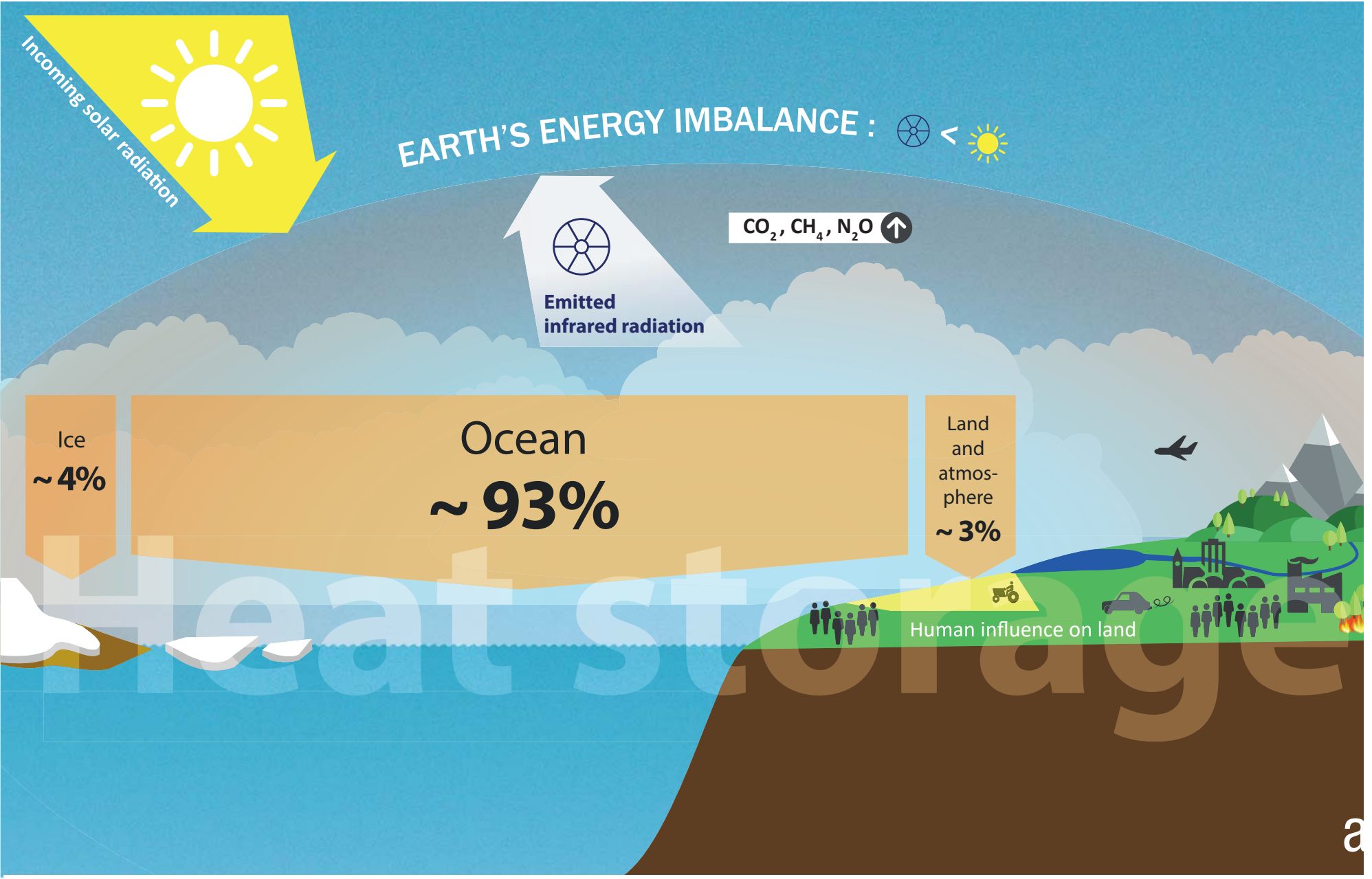

EARTH'S ENERGY IMBALANCE : $\theta<$ 莎

Atmospheric temperature

(1)

Atmospheric moisture $\uparrow$

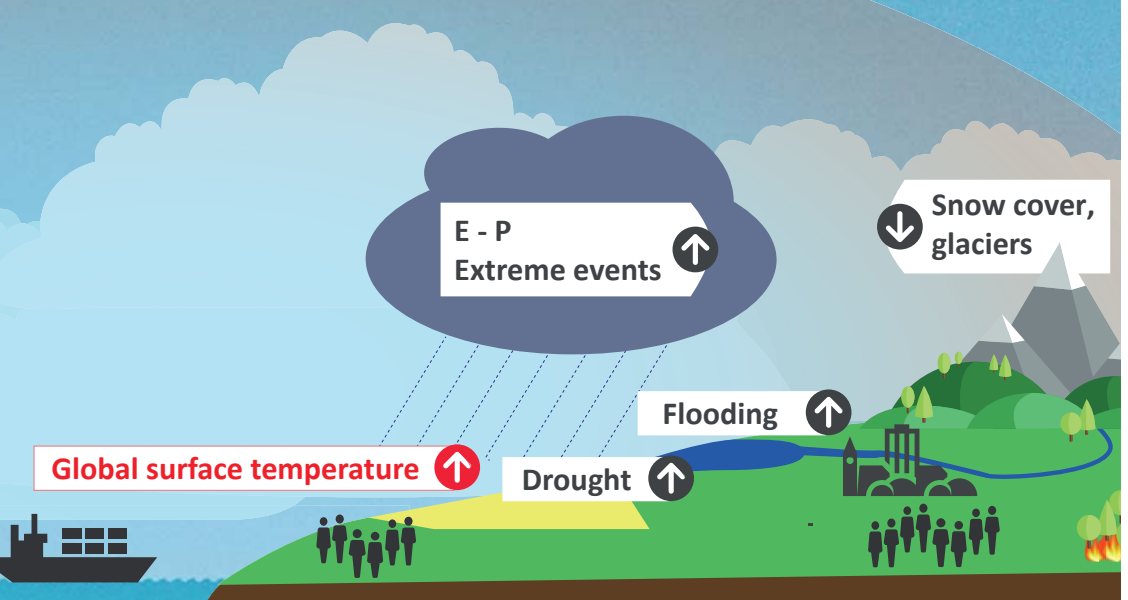

$\downarrow$ Sea ice

Global mean sea level $\boldsymbol{\uparrow}$

Coastal flooding, erosion $\uparrow$

Ocean heat content $\uparrow$

Ocean mass $\uparrow$ 

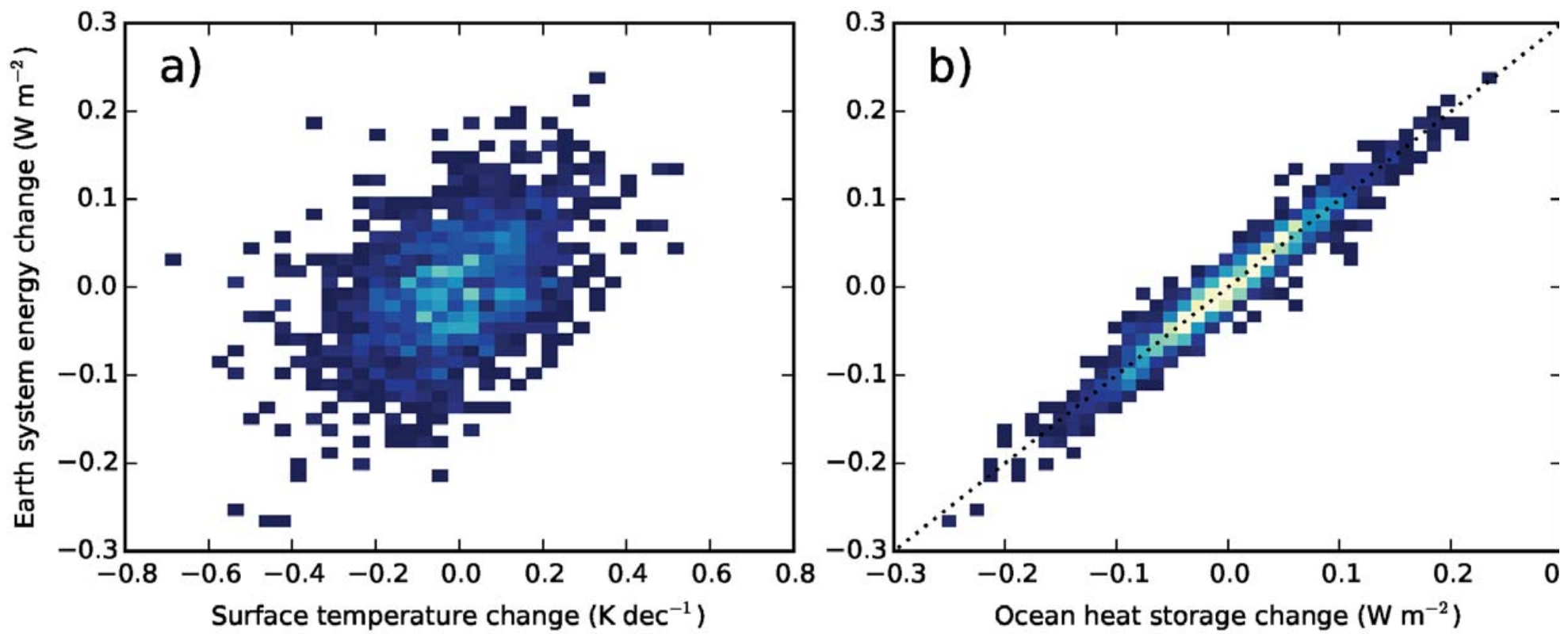

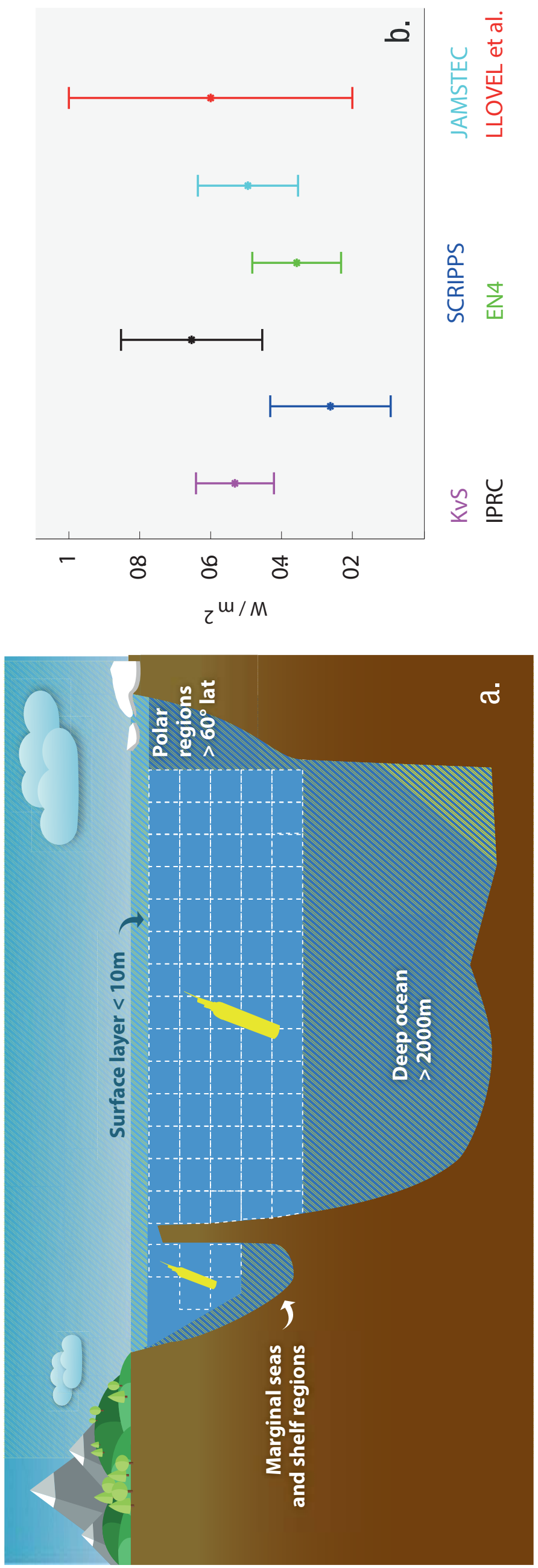